\title{
Heroin addiction, ethics and philosophy of medicine
}

\author{
Henk ten Have and Paul Sporken Rijksuniversiteit Limburg, The Netherlands
}

\section{Authors' abstract}

This article discusses various ethical and philosophical aspects of heroin addiction. It arose as a result of the plan by the Amsterdam city council to supply free heroin to drug addicts.

The objective of treatment of heroin addicts is ambivalent because what is in fact a socio-cultural problem is transformed into a medical problem. The characteristics of this treatment are made explicit through a philosophical analysis which sees the medical intervention as part of a strategy aimed at achieving social normalisation. The reason why such a social control function is practised by physicians is discussed, as well as the reason why heroin users in particular are the object of such a process. In this paper, heroin addiction is considered primarily as a cultural problem. The consequences of this for treatment and ethics form the conclusion.

\section{Facts and figures}

During the last ten years, Amsterdam has developed into the heroin centre of Western Europe. At present there are approximately 10,000 addicts, who need 500 million guilders (well over 100 million pounds) per annum to purchase their drugs. The major part of this sum is obtained from theft, amounting, in total, to 2000 million guilders.

In 198353 people died in Amsterdam from heroin overdose, use of impure heroin, and combined use of heroin, alcohol and barbiturates. (In 1982 the figure was 34).

Health organisations estimate that 1000 heroin prostitutes are active in the city. On examination of 200 of these prostitutes, syphilis was diagnosed in 5 per cent, gonorrhea in 44 per cent, and trichomoniasis in 37 per cent (1). To finance their requirements of heroin, these prostitutes need approximately five to ten sexual contacts a day. They constitute therefore an extensive cause of infection with venereal diseases, particularly as they abstain from medical control and treatment.

Recently other alarming developments have

\section{Key words}

Drug abuse; heroin addiction; medical ethics; life-style; philosophy of medicine; social control; tutelage and contract. occurred. Police action in the centre of Amsterdam has caused heroin use and illicit heroin traffic to spread to other parts of the city. Other cities are becoming increasingly involved in heroin addiction. In addition, heroin use is starting at a progressively early age. Finally, an increasing number of addicts are using different kinds of drugs at the same time.

\section{The frustration of fighting drug abuse}

The proliferation of heroin use has taken the government and health authorities by surprise. For a problem of this size and nature existing structures an current methods have proved to be inadequate.

Police and the law have little hold on the crimines subculture of addicts and dealers. The fighting of heroin use often has paradoxical effects. Police action, for instance, leads to a higher price for heroin on the black market; this induces criminal behaviour of heroin users, which in turn evokes extra efforts by police and law.

The increasing number of convictions for heroin dealing takes up a lot of prison capacity. In addition, this category of prisoners makes special demands on the warders. In practice, it appears to be impossible to exclude drug use and drug traffic from prisons.

Heroin addicts are not inclined to use health facilities. As a result health organisations themselves instigated attempts to contact drug users, removing treatment to the street (for example, 'pub-like' meeting places in various districts, each with a professional dealer). Later, an experiment in supplying methadone was started.

None of these methods were very successful. The meeting places became hot beds of illicit traffic; some were set on fire; others eventually closed. The methadone experiment has not been sufficiently evaluated yet, but it seems that it was not only relatively unsuccessful but that it also encouraged the use of other drugs such as cocaine. Recently new proposals for treating the drug problem were put into effect. In the autumn of 1980 the mayors of Rotterdam, The Hague and Utrecht pleaded for compulsory admission and treatment of drug addicts in medical institutions. At the end of 1983 the Amsterdam City Council proposed a plan which combined supplying 
300 problematic users with heroin, under medical supervision, with expanding the narcotics division and adopting a tougher line towards crime in general and the drug traffic in particular. The last part of the plan was welcomed, the first rejected, by police and lawyers, as well as by the central government and the Dutch Society of Physicians. Very recently the plan was revised, but not in essence: free heroin was to be distributed experimentally to a small number of addicts (from 5 to 50), and where there was a medical indication only (2). Although the Department of Health turned down this plan too, political discussions on its acceptability are still going on.

\section{Assumptions and presuppositions}

The attitude towards the drug problem is characterised more and more by defeatism. The aim of treatment seems to have shifted from therapy to containment: instead of helping the heroin user to get rid of his addiction, efforts are made to fight the expansion of heroin use, to fight public nuisance and crime and to maintain law and order as much as possible. Sometimes there is even an attempt at rationalisation of this attitude; it is assumed that, for many, addiction is only a temporary episode in life, which will pass of its own accord (3).

The doubts about the aims of treatment of heroin addiction have their source in the ambivalence of the presuppositions about the nature of the problem on the one hand, and the personality of the drug addict on the other.

\section{1) DESCRIPTION OF THE PROBLEM}

It is assumed by many authors that heroin addiction is a medical problem, and that therefore medicine has a part to play in its cure. Drugs are discussed in medical terminology: there is a heroin 'epidemic', with a distinct focus, which involves transmission by direct contact and contamination of young people who have decreased resistance (4). This implies the existence of a disease, cause-and-effect relationships, and the need for treatment and prevention.

The physical damage which the addiction induces in the drug user himself is considered to be proof that heroin addiction is a medical problem. It follows that treatment must be aimed at counteracting the heroin dependence. Withdrawal, however, seems to work only temporarily, if at all. This indicates that apart from somatic factors, psychosocial factors are also involved. Most authors (2, 3, 4) agree that a transformation of the addict's life-style is necessary: detoxification must be followed by psychosocial rehabilitation. However, the claim that multiple factors contribute to the origin of heroin addiction is not true in every instance: the form of treatment commonly adopted reveals that doctors believe the fundamental cause of addiction is purely physical.

Whether heroin addiction is considered primarily as a result of psychosocial circumstances or as a result of somatic factors, there remains the question of why, in both cases, the addiction is assumed to be a medical problem. There are examples of hazardous life-styles and injurious behaviour patterns which are not considered as medical problems (for example, mountain climbing or boxing). Why are other stimulants (such as alcohol), which can be as harmful as heroin, tolerated in our society? Such questions point to another possible description of the problem: heroin addiction as a social problem. In the literature $(2,3)$, the pursuit of the management and social control of heroin addicts is also presented as the objective for intervention. Recent proposals for the provision of heroin aim at preventing crime and bringing addicts to a socially more accepted way of life. But, even in this description of the problem, physicians are given the role of supervisors and problem solvers. However, the role of medicine is hardly ever explicitly legitimised in terms of the damage heroin addiction causes to society. It is postulated that heroin use is inevitably connected with crime and that the somatic aspect of the former justifies the medical role in fighting the latter. Hence the ambivalence in the objective of treatment.

\section{2) THE DRUG ADDICT}

Addicts are considered to be 'difficult patients'. The treatment staff have to be on their guard towards heroin users; they will do anything to get drugs, they응 are unreliable, agitating, manipulative, and they play games with other people (5). They are considered to be poorly motivated to stop using drugs. This general mistrust of the heroin addict is apparent from numerous guidelines and recommendations for treatment including: Don't believe readily their statements; Perform a urine examination of those who have allegedly given up the habit; Be warned that addicts may consult a general practitioner under a false name (6). The heroin user is psychologically characterised by ego weakness: he is held to be unable to cope with stress, and to suffer from an inability to handle his problems in a meaningful way.

However, it is curious that many intervention projects stipulate that the addicts should be motivated towards the treatment. Conditions are imposed upon the participants of a therapy as well as those who get a free supply of heroin. General practitioners in Amsterdam, for instance, only help addicts when they are sufficiently insured against medical costs, have accommodation, can handle medicines well and keep their promises (7). This points to another ambivalence in the attitude towards heroin users: if they want to be helped they have to meet conditions which they are incapable of meeting because of their addiction.

\section{Heroin addiction as a socio-cultural problem}

The ambivalence of the attitude towards both the nature of the problem and the personality of the drug user seems to be responsible for the uncertainties regarding the aims of treatment: should it be directed to the interests of the addict or those of society? 
From a philosophical point of view an explanation can be given for this ambivalence.

The aim of treatment may be defined as either to achieve abstinence from heroin use or to neutralise the social consequences of such use. In fact treatment tries to achieve both. The intervention of the treatment staff is aimed at controlling the problem: the object of 'assistance' is also the object of 'correction and normalisation'.

The treatment of drug users is part of a series of strategies to control the social 'body'; one can understand its nature more clearly against the background of what has been described by Donzelot and Foucault as 'the proliferation of political technologies that invested the body, health, modes of subsistence and lodging - the entire space of existence in European countries from the eighteenth century onward' (8). These political technologies focus on the production of a new behaviour pattern in specific groups of the population; they are not set up to suppress and punish undesirable behaviour but to supervise it, to steer it into other channels. They function by applying the tutelage-and-contract model. If individuals comply with defined standards they are allowed a certain autonomy and responsibility for their own behaviour. Positive integration of the majority of the population is accomplished through an informal contract. If individuals escape from this normalisation process by not complying with the contract or when small groups with a common interest are formed, which complicate normalisation or make it impossible, autonomy will be taken away and replaced by tutelage. A negative integration is accomplished through a chain of interventions, adapted to the various deviations from the norms. This second level of regulatory and corrective techniques has to be visibly present to enable the first level to function. One of the incentives to accept the standards is the threat to take away autonomy - the risk of tutelage. Adequate functioning of the normalisation process under the contract model necessarily presupposes the existence of marginal groups to which the tutelage model applies.

The ambivalence towards the drug problem and the drug user becomes more prominent against the background of this social supervision mechanism and the cultural values and standards which play a part in it. Two questions arise: 1 . Why did the social supervision function come to rest on physicians? 2 . Why, of all aberrant and noxious behaviour patterns and habits, did the use of heroin become the target of supervision mechanisms?

\section{Why physicians?}

The French philosopher Michael Foucault (9) has described the way in which, at the end of the 18th century, a mutation occurred in medical attitudes - in the medical discourse - and how at this period medicine came to articulate the fundamental values of the bourgeois culture. In this context, it is important to note his idea that modern medicine has become an essential element of a political programme, focused on control over life, illness and health, 'une bio-politique de्. la population'. Medicine has come to function as the ? privileged medium through which social interests are secured.

The present-day inclusion of medicine in the druge problem can be seen as part of this evolution. On the one hand, the neutral, objective and rationalising medical language masks the normative character of interventions. The primary interest of society in w regulation of heroin use is concealed by the emphasis of medical discourse on the interest of the addict. The medical language seems to serve as a justification of supervision. Further, the individualisation of the? addiction issue diverts attention from the norms and values from which the issue is approached.

On the other hand, drug users are induced to comply with the social norms, not through brute force but by the creation of an exchange mechanism. They will bew supplied with methadone or heroin in exchange fo도 being submissive and manageable towards the treatment organisations. This exchange mechanism is under medical supervision. Moreover, it is precisely the medical context which leaves the possibility of forcible constraint open, because addiction is medically characterised as an effect which happens topeople, as something which affects the free will, th@ autonomy of man himself. The attraction of $\mathbf{w}$ er exchange is increased for the addicts becaßs constraint or tutelage are ever present and justifiable possibilities.

The function of medicine as a social supervisionf mechanism is reflected in actual intervention projects $\underset{\Omega}{\mathbb{D}}$ Despite the fact that programmes for supply of heroir and methadone have had only limited success in severas countries, they are again being proposed. They do not offer help against the addiction itself nor against itș. background causes. The only appeal seems to lie in their function as a policy of social control: a sub population dependent on social institutions can be created. Rehabilitation programmes have more or less. the same function: dependence on drugs is exchange 6 for dependence on the therapist, the self-help group o₹ the therapeutic community.

\section{Why heroin users?}

As already mentioned, there are a lot of activities and addictions that are dangerous in themselves and towards which our society does not act as stringently a尺 towards heroin use. In itself, pursuing pleasure by drinking alcohol, smoking cigarettes of mountaineering is not disapproved of. Why is heroif use an exception? The social nuisance it causes canno in itself be a sufficient reason: drinking alcohol can have serious social effects as well. Moreover, crime is not necessarily related to the use of stimulants such as heroin and alcohol. Does heroin use perhaps evoke of special reaction because it is a 'moral menace', a田 affront to the basic values of our culture? We do no usually disapprove of pleasure if it implies an 
achievement or increases the ability to achieve, if it is not an impediment to our functioning in society, if it does not obstruct our productivity, our contribution to society as a whole. Besides, we consider life as a task which, however difficult, ought to be accomplished; temporary escape and diversion from this task is tolerated - total withdrawal, however, is not. Man is homo respondens, which means: he can be addressed by his fellow man and is responsible to them. He is also a creature who is obliged to pursue self-realisation in solidarity with others.

The heroin user seems to be considered as one who rejects these cultural values. He refuses the task of selfactualisation; he refuses to contribute positively to society. He allows himself to become a 'drop-out', he turns in on himself and withdraws from social obligations. At the same time, besides rejection of social relationships heroin addiction implies a parasitical use of these very relationships. This does not necessarily include illegitimate appropriation of other people's properties; the very life pattern of the heroin user, which is based on the assumption that there are at least some members of society who do not pursue immediate satisfaction of pleasure illustrates this parasitism. That could be one of the reasons why these 'parasites on society' are morally condemned and more vehemently reacted against than those with other hazardous life-styles. It could explain why repeated efforts are made to induce them to function within society again, or at least to convert parasitism into commensalism.

These ideas could also explain the preconditions for treatment. As with every member of society, demands may justifiably be made on a heroin user: 'A therapy without sufficient demands will lead to continuation and deterioration of the addiction' (5). Good members of society can cope effectively with problems, they are capable of sublimating or neutralising their tensions, uncertainties and fears. By a (formal or informal) therapy contract, the drug user will be addressed in his role as a member of society and stimulated towards positive integration. If he does not stick to this contract, he demonstrates his ego-weakness, his own insignificant capability, and his lack of responsibility $(10,11)$. Offering a therapy posits the basic value of autonomy and at the same time legitimises its violation (through tutelage and negative integration).

\section{Treatment and ethics}

From the above ideas, it becomes clear that heroin addiction and the treatment offered cannot be reduced to a medical problem: the medical aspects are deeply embedded in socio-cultural values. Thus, the ethical intricacies it causes do not belong only to the field of medical ethics but to social ethics more generally. Ethical aspects have already been mentioned in the discussion of several elements of this problem, but we would now like to present them explicitly.

The use of heroin is generally considered as a moral evil, for several reasons. Heroin addicts ruin their health and life; they lapse into crime and prostitution. According to the image of man in our culture, selfrealisation in solidarity with others is considered as a fundamental moral obligation. According to that very image of man, respect for individual freedom and personal responsibility is rated highly. If somebody ruins his health by being addicted to stimulants, people may consider it ethically wrong but they will not consider it a sufficient reason to interfere as long as no harm is done to others.

So why do people want to introduce free supplies of heroin to addicts? The fact that one is not able to give efficient treatment cannot be the exclusive reason, because this is also the case in other forms of addiction. Nor are the effects it has on one's health a sufficient reason, because on this point, the difference is only gradual. The real reason - in our opinion - is that heroin addiction implies serious negative consequences for society. Those who take a close interest in maintaining public order find a justification for free provision through reasoning that people who have been addicted for a long time are 'hopeless cases' who would perish anyway and that free provision of heroin will at least put an end to criminality.

From the viewpoint of social ethics, it can be said that while fighting criminality is good, the end does not justify the means, because a group of people will be abandoned and even sacrificed as a means of preventing social disorder. In practice this means institutionalising, pardoning and subsidising 'death therapy' for people whom we consider to be 'hopeless cases'. This is an inadequate and ethically unacceptable way to maintain public order.

The co-operation of physicians in such an experiment is hard to justify. Their task would, amongst others, consist of determining a 'medical standard' by which to select addicts for free heroin provision, and of supervising the correct use of the heroin. This seems to be a spurious use of health care. In fact, it means that the physicians would actively cooperate in severely damaging individual health, and thus in endangering life, in order to prevent greater harm, not for the good of those individuals (which is a common and proper medical objective) but only for society's sake.

From the viewpoint of treatment ethics too, free provision of heroin appears to be unacceptable, for the ethical norm of treatment is determined by the authentic interests of the person requiring help. Free provision of heroin does not serve these interests. It inevitably means reinforcing the person's addiction, and is a further encouragement towards a total ruination of the addict's health. The fact that therapy often has no positive effect is not sufficient to justify this method of treatment.

\section{Conclusion: a better solution?}

Our criticism would be more forceful if it were 
accompanied by an adequate solution to the problem, which we do not have. However, we would like to propose that the following be taken into consideration.

i. Heroin use can be interpreted as a socio-cultural problem. As such it represents a fundamental questioning of societal values and norms, a sign of some people's need for consciousness alteration and escape from the meaninglessness of social life.

ii. In modern culture, there is a strong tendency to medicalise the use of heroin because medicine has become one of the most powerful mechanisms to reinforce the basic cultural norms and values.

iii. Through calling heroin use a medical problem, society tries to reinforce those values which have become meaningless for some of its members. However, medicine cannot offer an adequate solution as long as it functions as a social supervision mechanism, articulating the prevailing cultural values. iv. Ethicists and philosophers ought not to restrict themselves to an analysis of the moral aspects of the medical management of heroin addiction (for example, personal freedom $v$ paternalism). They should also analyse the role of medicine in defining and managing the drug problem. If medical practice results in diverting criticism away from cultural values by individualising social problems, a critical analysis of this process can help to throw more light on the philosophical basis of medical practice.

\section{Acknowledgement}

We are indebted to Helma van der Linden, Francy van Lieshout and Marti Roos for their help with composing the English text. Our thanks are also due to Professor Gavin Mooney, University of Aberdeen, who has made helpful comments on the drafts of this paper.

Henk ten Have, PhD is a physician and philosopher, and is Professor of Philosophy (on behalf of the Radboudstichting, a Catholic Foundation in the Netherlands which stimulates research into the relationship

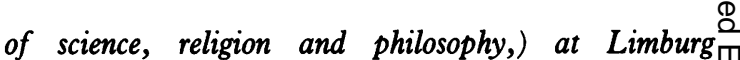
University, Maastricht, the Netherlands. Paul Sporken is $\overrightarrow{\bar{D}}$. a Doctor of Divinity and Professor of Medical Ethics at Limburg University, Postbus 616, 6200 MD, Maastricht, $\Rightarrow$ the Netherlands.

\section{References}

(1) Hoek J A R van den, Jansen Schoonhoven F, Arnhem A van, Coutinho $R$ A. Seksueel overdraagbare $\vec{\omega}$

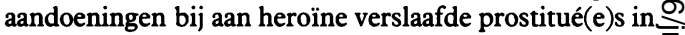
Amsterdam, 1982. Nederlands tijdschrift voor geneeskunde 1984; 128: 272-274.

(2) Brussel G H A van, Vink J. Medische indicatie tot $\overrightarrow{-}$ heroïneverstrekking in Amsterdam. Nederlands ${ }^{-}$ tijdschrift voor geneeskunde 1985; 129: 365-367.

(3) Rengelink H. Hulpverlening aan drugverslaafden. Nederlands tijdschrift voor geneeskunde 1984; 128: 259-O 260.

(4) Geerlings P J. Medische aspecten van de heroïneverslaving. Nederlands tijdschrift voor geneeskunde ${ }_{\varnothing}$ 1979; 123: 1148-1154.

(5) Levine S, Stephens R. Games addicts play. Psychiatric quarterly 1971; 45: 582-592.

(6) Staatstoezicht op de Volksgezondheid. Brief aan alle $\vec{\bullet}$ artsen in Nederland betreffende de ambulanes o or behandeling van verslaafden aan opiumwetmiddele Leidschendam, 1981.

(7) Braber L C, Vries D de. Hulp aan heroïneverslaafdeñ door huisartsen. Nederlands tijdschrift voor geneeskunde 1984; 128: 264-266.

(8) Donzelot J. The policing of families. New York: Pantheon $\stackrel{\triangle}{\triangle}$ Books, 1979: 6. See also: Hodges J, Hussain A. La police $\vec{F}$ des familles. Ideology and consciousness 1979; 5: 87-123.

(9) Foucault M. Naissance de la clinique. Une archéologie du regard médical. Paris: PUF, 1963.

(10) Sporken P. Begleitung Suchtkranker als zwischenmenschliches Geschehen. Ethische Ueberlegungen. Kassel: Nicol Verlag, 1983.

(11) Sporken P. Begleitung in schwierigen Lebenssituationen. Ein Leitfaden für Helfer. Freiburg in Breisgau: Herder Verlag, 1984. 